\title{
TRADUZIR PARA NÃO ENTENDER: SOBRE O MULTILINGUISMO NO TEATRO ATUAL
}

\author{
Ruth Bohunovsky 1 \\ 1Universidade Federal do Paraná, Curitiba, Paraná, Brasil
}

\begin{abstract}
Resumo: Partindo da premissa de que a coexistência de diferentes línguas é um fenômeno presente no teatro desde seus primórdios e que pode ser apresentada ao público de modos diferentes, este artigo examina duas montagens teatrais atuais, ambas explorando formas inovadoras de exibir o multilinguismo. Nos dois casos, os diretores optaram por traduzir peças originalmente escritas em uma única língua para outras línguas ou variantes linguísticas, no intuito de criar um estranhamento ou reforçar a sensação de não compreensão. O artigo descreve consequências desse cenário multilíngue para a tradução e a recepção de peças teatrais.

Palavras-chave: Teatro Multilíngue; Tradução Teatral; Franz Grillparzer; Wadji Mouawad
\end{abstract}

\section{TRANSLATE TO NOT UNDERSTAND: ABOUT MULTILINGUISM IN TODAY'S THEATER}

\begin{abstract}
Starting from the premise that the coexistence of different languages has been a phenomenon in the theater since its beginnings and in different forms, this paper deals with two current theater productions, both exploring innovative forms of multilingualism. In both cases, the stage directors chose to translate plays originally written in a single language into other languages or varieties, in order to create a strangeness or reinforce the feeling of not understanding. Such a multilingual theater staging has consequences for theatrical translation and the reception of dramas, which are discussed in this paper.
\end{abstract}

Keywords: Multilingual Theater; Theater Translation; Franz Grillparzer; Wadji Mouawad 


\section{Introdução}

A vida é multilíngue, e a história da literatura e do teatro está repleta de obras que, de diversas maneiras, procuram lidar com esse fato. Existem inúmeros exemplos de textos teatrais que contêm traços de alguma forma de multilinguismo literário - que pode ser entendido como a representação de falantes de diversas variantes de uma idioma (por exemplo, a língua padrão, dialetos, socioletos etc.) ou de línguas diferentes. No seu panorama sobre formas e funções do multilinguismo teatral, Claude D. Conter $(2017)^{1}$ faz diferença entre dois tipos básicos: primeiro, o multilinguismo latente, quando a língua em que a peça foi escrita não coincide com o espaço linguístico-cultural no qual o enredo está ambientado, como em Hamlet, de Shakespeare; ou quando uma peça é escrita em apenas uma língua, embora tematize o fato de as personagens serem falantes de diferentes línguas como, por exemplo, na tragédia Zaïre, de Voltaire. Essa peça ambientada na Jerusalém ocupada pelo curdo Saladino tem, entre suas personagens, além do sultão, cruzados franceses (Conter: 280). O segundo tipo seria o multilinguismo manifesto. Nesse caso, o texto teatral - e/ou a encenação - contém de modo explícito diversas línguas ou variantes linguísticas. Tradicionalmente, para traçar uma personagem de origem linguística diferente daquela que predomina na obra, tem-se recorrido a sinais reconhecíveis pelo leitor ou espectador, como o uso de palavras estrangeiras, desvios fonéticos, erros gramaticais, morfológicos ou sintáticos ou expressões em língua estrangeira, muitas vezes criando um efeito cômico e reforçando estereótipos culturais. Na tradição do teatro europeu temos exemplos de peças multilíngues de Aristófanes e Plauto, na Commedia dell'Arte, nas obras de Shakespeare, Lope de Vega e Goldoni, entre outros (Weissmann).

\footnotetext{
${ }^{1}$ Nesse trabalho, o autor trata também de formas do multilinguismo literário que não serão abordadas no presente artigo, como o caso de autores ou dramaturgos que escrevem em mais de uma língua (p.ex. Samuel Beckett ou Peter Handke) ou a tradução de dramas para a língua de sinais.
}

Cad. Trad., Florianópolis, v. 41, no 2 p. 382-399, mai-ago, 2021. 
Na maioria dessas peças, pressupõe-se que o público seja capaz de entender as frases expressas em língua estrangeira ou que tais passagens não sejam imprescindíveis para o entendimento do drama. Conforme já mencionado, muitas vezes emprega-se apenas desvios fonéticos ou gramaticais que não comprometem a compreensão, mas deixam evidente que seu falante representa um estrangeiro. Assim, quando falamos de peças multilíngues, pressupomos que a compreensão por parte do público não seja comprometida. Ultimamente, há indícios de que essa premissa precisa ser repensada ${ }^{2}$.

Como já apontado em trabalhos recentes, nas últimas décadas, a montagem de peças multilíngues parece ter se tornado cada vez mais frequente (Conter; Weissmann). Há duas razões principais para isso. Em primeiro lugar, o público contemporâneo é marcado pela migração e a globalização, é poliglota e familiarizado com as muitas facetas, positivas e negativas, da heterogeneidade linguística. Certamente isso vale ainda mais para os países europeus do que para o Brasil, mas mesmo aqui a presença de línguas estrangeiras tem se tornado mais frequente. Em segundo lugar, deve-se mencionar a influência de novas possibilidades tecnológicas, como a legendagem eletrônica de peças teatrais, que têm aberto novas possibilidades estéticas e dramatúrgicas, permitindo a compreensão de algo dito em outros idiomas no palco.

A legendagem permite que a presença de diferentes línguas em cena não impeça a compreensão. Porém, é interessante notar que alguns autores e diretores têm optado por peças ou montagens multilíngues para encenar de modo explícito justamente a não compreensão. Na peça Till, da escritora, poeta e dramaturga japonesa Yoko Tawada, que reside em Berlim e escreve em japonês e alemão,

\footnotetext{
${ }^{2}$ Vale lembrar aqui outro exemplo de "não compreensão" no teatro, a "língua não língua" (grammelot), fenômeno conhecido pelo menos desde a Commedia dell'arte e que imita de modo lúdico, muitas vezes com intuito satírico, a sonoridade de uma determinada língua, sem produzir qualquer conteúdo semântico. Ou seja, nos grammelots não há o que possa ser compreendido. No presente artigo, o foco está em línguas reais faladas no palco para um público que não domina esses idiomas.
}

Cad. Trad., Florianópolis, v. 41, no 2 p. 382-399, mai-ago, 2021. 
temos duas linhas de ação, uma em alemão e outra em japonês, com alguns momentos de contato marcados pela não compreensão entre os personagens em nível linguístico. Grande parte do público entende apenas uma parte da peça. Trechos não compreendidos convertem-se em cenas sonoras e visuais. Assim, a peça torna-se uma "alegoria das diferenças linguísticas em nível global, que podem ser uma fonte vital da experiência humana" (Dembeck \& Uhrmacher 15). A "não compreensão" transforma-se numa "componente da estética teatral" (Conter 288). Trata-se de uma proposta de representar tanto a não compreensão linguística quanto as possíveis formas de superá-la através de "formas pré-linguísticas da mediação comunicativa" (Weissmann 175). Ou seja, o palco transforma-se num lugar para encenar a não compreensão. Na peça de Tawada, haver duas línguas é parte central para atingir esse objetivo.

Diferentemente de textos dramáticos escritos em mais de uma língua, os dramas que nos interessam aqui foram escritos originalmente em uma única língua e somente na sua encenação se tornaram peças multilíngues. Seu caráter multilinguista resulta não de uma decisão dos autores, mas dos diretores. $\mathrm{O}$ fato de haver diversas línguas em cena pode abrir novos acessos interpretativos para uma peça, pois o público já conhece por experiência própria o emaranhado linguístico que cada idioma implica, não apenas de sons, significados e gramáticas variados, mas também de conotações que remetem a relações políticas em nível nacional e/ou global. $\mathrm{Ou}$ seja, o que dizemos é importante, mas a língua que escolhemos para dizê-lo pode ser mais importante ainda para definir não apenas quem vai nos ouvir, mas também como aquilo que dizemos será entendido. A língua é decisiva para construir nossa identidade, mas também para definir a identidade que os outros nos atribuem, independentemente de nossa vontade. E o teatro pode ser um lugar onde se procura problematizar tanto as múltiplas implicações da comunicação entre falantes de diferentes idiomas (que, ao contrário do que o Google Tradutor ou outras ferramentas de tradução parecem sugerir, nem sempre é isenta de problemas culturais e/ou políticos) como as inúmeras relações entre língua(s), identidade(s), 
nacionalidade(s) e política(s). Em relação à tradução teatral, isso traz novos desafios, novas modalidades e novas lógicas: nos casos aqui apresentados, não se precisa mais de um tradutor para verter uma peça escrita em uma determinada língua para outra, mas para traduzir, por exemplo, trechos de uma peça para um idioma que o público não entende, para uma variante diferente, ou para traduzir uma peça monolíngue para as línguas que correspondem aos personagens no seu ambiente de ficção, independentemente se serão entendidos ou não pelo público.

As duas montagens aqui em foco estrearam em importantes teatros de Viena, o Akademietheater e o Volkstheater, em 2019. Trata-se de duas peças bastante diferentes, um clássico da literatura austríaca nacionalista do século XIX e uma peça escrita em 2017, que aborda os conflitos políticos do Oriente Médio na atualidade. As línguas que seus diretores levaram ao palco não são as mesmas, nem os contextos políticos aos quais remetem. Porém, ambos os diretores tiveram o mesmo objetivo ao lançar mão de mais de uma língua: chamar a atenção para a (frágil) relação entre língua e a nacionalidade e, a partir disso, questionar discursos essencialistas, tão em voga no cenário político mundial.

\section{Ventura e Fim do Rei Ottokar ${ }^{3}$, de Franz Grillparzer (1791-1872): traduzir para desconstruir}

A peça König Ottokars Glück und Ende [Ventura e Fim do Rei Ottokar] é ambientada em Praga no contexto histórico do século XII e expõe uma mudança de poder que produziu consequências históricas. Ottokar, rei da Boêmia, encontra-se no auge de seu poder político. Acabou de ganhar uma batalha importante contra os húngaros e planeja ampliar seu domínio na região. Tudo indica que ele será eleito imperador do Sacro Império Romano-Germânico. Porém,

3 Disponível em: < https://www.volkstheater.at/stueck/koenig-ottokars-glueckund-ende/ > ; a estreia foi 8 de janeiro de 2019.

Cad. Trad., Florianópolis, v. 41, n 2 p. 382-399, mai-ago, 2021. 
após um comportamento ofensivo de Ottokar contra sua ex-esposa (que ele havia trocado pela filha do rei da Hungria, por interesse político) e contra alguns aliados, o conde Rudolfo de Habsburgo, que está em Praga apenas de passagem, a caminho de seu castelo na região de Aargau na Suíça, vai ganhando destaque político e acaba coroado imperador. A peça termina com uma cena de humilhação de Ottokar por seu adversário Rudolfo, que sai como grande vencedor - uma cena ideal para fundar uma tradição discursiva acerca do momento inicial do Império dos Habsburgos, responsável até hoje pela autoimagem dos austríacos ${ }^{4}$. Numa conversa com o diretor Dušan David Pařízek, o dramaturgista ${ }^{5}$ Robert Koberg afirma que a peça fornece para os austríacos "tudo o que gostam de ouvir e ler sobre si mesmos": enquanto Ottokar é apresentado como um político egoísta, ambicioso, megalomaníaco e faminto de poder, Rudolfo surge como uma figura humilde, religiosa, sensata e diplomática (Koberg s.p.). A parte mais famosa da peça é o poema "É um bom país" [ES ist ein gutes Land], um hino às belezas e vantagens naturais da Áustria e da natureza pacífica e igualmente humilde de sua população. Trata-se de um texto reproduzido desde sua estreia em milhões de livros didáticos destinados às escolas austríacas. Ou seja, estamos lidando com uma peça modelo da ideologia nacionalista, partindo da premissa da existência de nações e povos de características bem definidas. Uma ideologia responsável por vários conflitos violentos e guerras que marcaram a Áustria e o mundo nos dois últimos séculos e que nada indica haver sido sobrepujada no começo da década de 2020. Ao mesmo tempo, trata-se de uma peça de alta qualidade dramatúrgica e com figuras traçadas com inteligência psicológica, uma obra fulcral do cânone austríaco e que, como sugere o contínuo interesse por parte dos teatros, de diretores e do público, ainda merece ser encenada e discutida.

\footnotetext{
4 Sobre a importância desse "mito dos Habsburgos" na literatura austríaca $c f$. Magris (2000).

${ }^{5} \mathrm{O}$ termo "dramaturgista" refere-se à pessoa responsável, entre outras funções, por "intervir diretamente na produção dos vários espetáculos provendo suporte crítico ao encenador para a interpretação de cada texto" (Paroni s.p.).
}

Cad. Trad., Florianópolis, v. 41, no 2 p. 382-399, mai-ago, 2021. 
Quando Franz Grillparzer escreveu Ventura e Fim do Rei Ottokar, era funcionário público do Império dos Habsburgos e um aclamado dramaturgo, famoso por dramas como Die Ahnfrau [A ancestral], Sappho [Safo] e Das goldene Vliess [O velo de ouro] ${ }^{6}$. Para sua "tragédia em cinco atos" sobre a suposta origem do Império dos Habsburgos, usou fontes medievais e narrativas históricas da época, interpretando-os em prol da construção do mito da família imperial, à qual ele servia, e ao contexto histórico no qual vivia. A peça teve sua estreia em 1825 no teatro municipal de Viena, o famoso Burgtheater. Desde então, só nessa cidade, foi encenada mais de vinte vezes, com montagens diferentes. Em 1955, após o término da restauração do Burgtheater, destruído por bombas no final da II Guerra Mundial, foi justamente essa peça a escolhida para reinaugurá-lo, em um dos inúmeros gestos do governo austríaco da época no intuito de reconstruir uma identidade austríaca positiva.

Grillparzer escreveu sua peça em versos em língua alemã, um alemão metrificado nos moldes de seu tempo. Ou seja, no texto escrito pelo dramaturgo, são os nomes dos personagens e o enredo que indicam sua origem geográfica e dinástica e não a língua utilizada, pois todos falam alemão.

Por que levar, hoje, uma peça com tal teor nacionalista ao palco? E como fazê-lo? Num contexto político atual, seria bastante improvável algum renomado teatro europeu optar por sua encenação com o objetivo de contribuir para a perpetuação do mito heroico da nação austríaca. Ao convidar um diretor tcheco, Dušan David Pařízek, o Volkstheater deu sinais de almejar uma nova leitura da peça. E Pařízek, conterrâneo de Ottokar, optou por "desfazer as poses de poder do drama histórico", como escreveu a crítica Margarete Affenzeller no jornal Der Standard, usando a própria peça para desconstruir e ironizar as ideias nas quais Grillparzer se

${ }^{6}$ É interessante notar que, nessa trilogia, Grillparzer usa diferentes modelos métricos para representar o multilinguismo nas falas de Medeia (uma estrangeira no país de seu marido Jasão) e dos gregos ( $c f$. Bernardes 2019).

Cad. Trad., Florianópolis, v. 41, no 2 p. 382-399, mai-ago, 2021. 
baseou ao escrevê-la. Para alcançar esse objetivo, o uso de outras línguas (e variantes) do alemão foi fundamental.

A montagem de Pařízek inicia com a entrada de Ottokar, representado pelo ator tcheco Karel Dobrý, em cima de um cavalo branco, proferindo frases em tcheco. Depois, continua sua fala em alemão. O conde, depois imperador, Rudolfo, representado pelo ator suíço Lukas Holzhausen, fala alemão - porém não a variante padrão conforme o texto original, mas um alemão com forte sotaque suíço. Lembrando que o histórico Rudolfo de Habsburgo nasceu e cresceu na região da Suíça, o uso dessa variante é coerente, embora isso não deva ser entendido como uma tentativa de recriar em moldes realistas a oralidade do século XII. Trata-se sim de usar uma linguagem que resulta da mistura de versos alemães escritos no século XIX com uma forma idiossincrática da oralidade do alemão suíço. O importante é que tal sotaque contraria a expectativa do público e, devido à sua sonoridade peculiar, torna-se motivo para o riso. Mas o efeito cômico (que por si só já contribui para a desconstrução do herói nacional Rudolfo de Habsburgo proposta pelo diretor) não foi a única razão para a escolha do sotaque. Na conversa entre Koberg e o diretor (publicada no programa da peça), o dramaturgista ressalta que Pařízek sempre atribui bastante importância a diferenças "que se expressam em dialetos e idiomas" e que esse fato colabora para deslocar Grillparzer do seu "pedestal clássico". Em um trecho dessa conversa, Pařízek aponta implicações de natureza política as quais levou em consideração ao decidir por um espetáculo multilíngue:

Obviamente, a linguagem de Grillparzer torna-se mais direta quando são atores de Praga ou do Aargau que se dão o trabalho de articulá-la. Com isso, põe-se em primeiro plano o ser humano, como indivíduo, e não é mais uma linguagem metrificada que se sobrepõe, em forma codificada, à natureza de cada ideia ou cada emoção. De repente, as figuras carregam consigo uma especificidade que ajuda à linguagem de Grillparzer a ganhar vida própria. Mas, o 
uso de idioletos tem algo mais que me interessa: o esforço para se chegar a uma língua comum mostra que o caminho até a assimilação cultural é muito longo. A imposição de uma língua oficial é [...] um instrumento de poder. [...] Grillparzer pretende definir a origem do mito da Áustria com uma narrativa épica heroica que remete até a Idade Média. É através da(s) língua(s) que nós mostramos que as posições das quais surgiu esse império colossal foram diversas. (Koberg $s / p$ )

Nessa explicação, Pařízek aponta alguns efeitos interpretativos que resultaram da tradução de algumas passagens dessa peça para 0 tcheco e o alemão suíço e que vão na contramão das premissas nacionalistas nas quais se baseia a versão original: as figuras "históricas" transformam-se em indivíduos comuns; a ideia da língua como um dos fundamentos da identidade austríaca se desconstrói, o "pai fundador" dos austríacos é, nessa peça, um suíço e fala uma variante com a qual os austríacos presentes no público não se identificam; a evidência de que uma língua oficial é sempre resultado de lutas de poder (cujos resultados possuem um certo grau de contingência) e não está enraizada em alguma "essência" de um "povo". Nada disso é novo, mas é através da tradução de partes do texto original para outra língua, ou para uma variante, que esses efeitos se apresentam numa peça que até agora tem sido usada para comprovar justamente o contrário. Rudolfo ainda profere as mesmas palavras, mas com sotaque suíço, e isso muda o sentido do que ele diz.

Para essa encenação, passagens de uma peça escrita em alemão foram traduzidas para uma língua que o público provavelmente não entende. Outros trechos foram traduzidos para uma variante do alemão com a qual o público não se identifica. A tradução torna-se aqui um meio para representar as dificuldades da compreensão, os mal-entendidos e incompreensões históricas. A ausência de legendas intensifica a sensação de não compreensão. Traduziram-se passagens da peça para o público não as entender e para estranhar a fala do "pai fundador" da "nação austríaca". 
Talvez até para mostrar que a realidade multilinguística da Áustria atual não significa a perda de uma língua ou cultura original e única, pois nunca houve uma língua ou cultura única. Assim, o multilinguismo no palco pode ser visto como um meio para atualizar uma peça histórica, canônica e relevante no contexto austríaco, ainda que ideologicamente problemática, tornando-a não só hodierna, mas também entrosada com as premissas de teorias culturais e linguísticas do mundo de hoje.

\section{Todos os pássaros ${ }^{7}$, de Wajdi Mouawad (*1968): traduzir para não entender}

Wajdi Mouawad é um dramaturgo libanês-francês-quebequense. Nasceu no Líbano, filho de pais cristãos maronitas e, aos 8 anos, devido à eclosão da guerra no Líbano, emigrou com a família para a França. Em 1983, mudou-se para o Canadá, onde se formou na Escola Nacional de Teatro em 1991. Mouawad escreve em francês e, atualmente, vive na França. Seu primeiro grande sucesso foi Incendies [Incêndios], que estreou em Montreal, em 2003, e trata da guerra civil no Líbano. O drama serviu como base para um filme com o mesmo título dirigido pelo canadense Denis Villeneuve e foi indicado para o Oscar em 2011. Desde 2016, Mouawad é diretor do Théâtre Nacional de la Colline, em Paris, onde estreou Tous des oiseaux [Todos os pássaros] em 2017.

A cena inicial da peça é um encontro. Numa biblioteca em Nova York, o jovem alemão judeu Eitan Zimmermann aborda - em inglês - a americana árabe Wahida. Começa assim uma grande história de amor, cuja língua é o inglês e que não se importa com identidades culturais, nacionais ou linguísticas; a base da união desse casal é a curiosidade científica, interesses comuns, o carinho, o amor. A relação dá certo até entrar em contato com as outras

\footnotetext{
${ }^{7}$ Disponível em: < https://www.burgtheater.at/produktionen/voegel > ; A estreia dessa montagem foi em 13 de setembro de 2019.
} 
línguas que formam as identidades dos dois. Eitan traz sua família da Alemanha para lhe apresentar sua noiva. Esta é rejeitada, sobretudo por seu pai, filho de um sobrevivente do Holocausto que entende sua existência como uma homenagem aos seus antecedentes judeus. À procura por respostas sobre a sua história familiar, Eitan viaja para Israel levando Wahida. Lá, é gravemente ferido num ataque terrorista e fica internado num hospital. Preocupada com seu estado de saúde, sua família também viaja a Israel. O novo encontro com Wahida não ameniza a rejeição da família de Eitan em relação a ela. Durante o tempo que fica em Israel, Wahida sofre com preconceitos dos israelenses em relação à sua origem, entra em contato com a realidade da Palestina e "descobre" sua identidade árabe. Enquanto isso, Eitan recebe alta do hospital e revela um segredo familiar que significa uma reviravolta para toda a identidade cultural e religiosa de sua família. Não há final feliz, nem para a família de Eitan, nem para o jovem casal. Os traumas da Shoah e os conflitos políticos do Oriente Médio não podem ser ignorados por ninguém desse grupo, nem por aqueles que acreditam ter rompido os laços com as histórias e identidades de seus antepassados.

A obra é resultado de uma colaboração entre Mouawad e a historiadora Natalie Zemon Davis, autora do livro Trickster Travels: A Sixteenth-Century Muslim between Worlds (2007). Nessa obra, a autora - que se autodenomina uma "judia na diáspora" à procura "por justiça e paz no Oriente Médio" (Davis $s / p$ ) - narra a vida de Hasan al-Wazzan, um árabe nascido em Granada no final do século XV que viajou pelo mundo árabe como diplomata do Marrocos até ser preso por piratas cristãos em 1518. Foi levado até Roma, converteu-se ao cristianismo para ser libertado da prisão e viveu na Itália até 1527 , quando voltou para o Norte da África e o Islã. Antes disso, ainda em Roma, escreveu livros sobre a África e o Islã para o público europeu, entre eles um best seller da época. Para Davis, Hasan al-Wazzan foi um "ícone da autorrepresentação e do entrelaçamento cultural" que havia "contado para os europeus que o mundo do Islã não é um lugar satânico, mas um lugar humano onde se encontra tanto o bom quanto o mal" (Davis $s / p$ ). Após os 
atentados de 9 de setembro de 2001, Davis percebeu que "a história de Wazzan poderia ser de grande importância" (Davis $s / p$ ) e iniciou as pesquisas para seu livro.

Quando o Stratford Shakespeare Festival resolveu fazer uma versão do livro para o teatro, Davis convidou Wajdi Mouawad. Ela já havia assistido à sua peça Incendies e afirmou: "sabia que Wajdi Mouawad ia entender meus objetivos com Trickster Travels" (Davis $s / p$ ). Durante a elaboração da peça, houve contato e colaboração constante entre os dois. A primeira versão foi escrita em francês. Depois, o texto foi traduzido para as quatro línguas dos protagonistas (alemão, árabe, hebraico e inglês). Mouawad ainda uniu atores e atrizes israelenses, árabes e alemães para uma montagem com essas quatro línguas ${ }^{8}$. Para Mouawad, a opção de pôr no palco um elenco que fala os mesmos idiomas dos personagens teve "consequências imensas". A razão seria, em suas palavras, serem pessoas "que compartilham comigo a mesma história de uma região que está se autodestruindo" (Davis $s / p$ ). Mas as consequências dessa decisão foram além da relevância desse compartilhamento de experiências pessoais do elenco. Numa resenha sobre essa montagem, Marcus Behrens aponta que, no intuito de "entender as tragédias do mundo atual”, Mouawad atinge as emoções de todo o público com o mesmo "impacto de um drama grego" (Behrens $s / p$ ). Sobre haver quatro línguas no palco, Behrens acrescenta que

\begin{abstract}
[...] o público francês se viu frente a um desafio: o enredo, contado em aproximadamente quatro horas, não contém nenhuma palavra em francês. Os atores e as atrizes falam inglês, alemão, hebraico e árabe - obviamente, tudo isso legendado em língua francesa. Mesmo assim, essa encenação - e com a vantagem de, diferentemente de muitos dos outros espectadores, eu entender inglês e alemão sem problema - foi uma das melhores que já vi em toda minha vida, mesmo sem entender nenhuma palavra de hebraico e árabe. (Behrens $s / p$ )
\end{abstract}

${ }^{8}$ A estreia desta montagem, sob direção do próprio Mouawad, foi no Théâtre Nacional de la Colline em 2018. Cf. < https://www.colline.fr/en/spectacles/all-birds > . 
A estreia em Paris e as apresentações posteriores na Alemanha, em Israel e nos Estados Unidos foram grandes sucessos. Segundo Davis, esse sucesso é resultado "não apenas da direção sensível de Wajdi e do trabalho excelente dos atores e das atrizes, mas também da mensagem da peça", que apela por transformar inimigos em amigos. Apesar dessa mensagem pacífica, o final da peça é nefasto e retrata uma "realidade trágica" (Davis $s / p$ ), uma versão atual de Romeo e Julieta. Além disso, mostra tanto a aleatoriedade de nossas identidades, sua vulnerabilidade e arbitrariedade, como a impossibilidade de nos livrarmos delas, sejam elas definidas por nós mesmos ou pelos outros. $\mathrm{O}$ fato de conceitos ligados à identidade (como nacionalidade, descendência, pátria, religião) possuírem uma alta relevância política, mesmo em regiões distantes do Oriente Médio (como na Europa e nos EUA) e até em regiões afastadas de focos de conflito real em termos de migração ou agressão bélica (como o Brasil) torna a peça tão atual, tão tocante, tão importante.

Nos países de língua alemã, a peça ganhou o título Vögel [Pássaros], numa tradução para o alemão de Uli Menke e publicada em forma de livro (2018), e montagens em diversos teatros ${ }^{9}$. Algumas foram só em alemão, outras nas quatro línguas, como aquela apresentada no Akademietheater, sob direção do israelense Itay Tiran. A estreia foi em setembro de 2019 e, assim como na versão montada pelo próprio Mouawad, o elenco se compôs de pessoas falantes das línguas de seus personagens. Os atores e as atrizes são exemplos vivos da permanente (re)construção de identidades e dos conflitos políticos sangrentos que associamos com o Oriente Médio. As identidades das quais trata a peça estão - como tantas outras - estreitamente ligadas a línguas e a suas variantes e sotaques. Todos temos essa experiência, cada vez menos pessoas vivem em uma comunidade fechada e linguisticamente homogênea, na qual não precisam refletir

9 Só na Áustria, em 2020, além da encenação em cartaz no Akademietheater, a peça estreou também em Graz (Cf. < https://www.schauspielhaus-graz.com/ play-detail/vogel/ > ) e em Salzburgo ( $C f$. < http://www.schauspielhaus-salzburg. at/spielplan/kinder-jugend1/VOeGEL_3491>), em montagens monolíngues.

Cad. Trad., Florianópolis, v. 41, no 2 p. 382-399, mai-ago, 2021. 
sobre sua identidade. Isso vale para as figuras fictícias da peça, mas também, por exemplo, para o ator Yousef Sweid (árabe cristão que nasceu em Israel e que, na peça aqui discutida, representa o árabe Wazzan): “O que a peça mostra não são clichês, isso é a verdade. É exatamente isso que está acontecendo, mas no dia a dia as coisas não são denominadas com palavras tão claras. Por isso, aprendi a aceitar a peça, pois nela existe uma verdade" (Kerlin 22).

Mesmo a atriz alemã Sabine Haupt, que na peça representa a personagem Norah, mãe de Eitan, não está alheia à questão da identidade, embora não tenha nenhuma relação pessoal com o Oriente Médio. Ela relata que sua "identidade alemã mudou” desde que mora em Viena: "antes de vir para cá, [a identidade alemã] não tinha nenhuma importância para mim, a não ser como um tema importante em reflexões sobre a história de meu país. Mas em Viena fui ofendida e ridicularizada por ser alemã" (Kerlin 20). Ou seja, a questão da identidade pessoal e suas possíveis implicações (políticas), assim como sua intrínseca relação com as línguas e variantes que falamos, não é estranha aos membros do elenco de Pássaros, mesmo àqueles sem nenhum envolvimento pessoal com o Oriente Médio ou o judaísmo. Podemos supor o mesmo do próprio público que assiste à peça e que se encontra numa sociedade marcada cada vez mais pela mistura (conflituosa ou não) de línguas, identidades, religiões e crenças políticas. Após a estreia de uma outra montagem de Pássaros no teatro de Stuttgart, na Alemanha, em que também se optou por uma versão multilíngue, Detlev Baur escreveu numa resenha que "o aplauso forte e prolongado da estreia mostrou que o público de Stuttgart havia ansiado por um teatro que o levasse a sério e que levasse ao palco, de modo sério, as questões da existência humana", num "debate aberto com o mundo" (Baur $s / p$ ).

A existência de várias línguas em cena intensifica o efeito emocional. O fato de a relação entre Eitan e Wahida funcionar bem enquanto a comunicação acontece apenas em inglês, o fato de a família e Eitan falar alemão e hebraico, o fato de Wahida começar a falar árabe quando conhece a Palestina, a sonoridade das línguas e aquilo que o público possivelmente associa com esses 
sons que nem sempre entende, as conotações políticas, histórias e emocionais - tudo isso acrescenta um sentido à peça que uma montagem monolíngue provavelmente não seria capaz de despertar com a mesma intensidade. Vale a pena ainda destacar que essa forma de multilinguismo teatral não acarreta nenhum efeito cômico, mas intensifica a dimensão trágica do enredo e simboliza uma das mensagens centrais da peça: as línguas que falamos não são apenas meios de transporte para significados e mensagens, mas estão inevitavelmente ligadas a questões de identidades, nacionalidades, religiões e histórias das quais não escapamos.

$\mathrm{Na}$ montagem de Itay Tiran, o público acompanha as falas em tradução legendada para o inglês e o alemão. As legendas foram integradas ao cenário, projetadas em grandes paredes que compõem os recursos cênicos. Ou seja, o objetivo do diretor não foi - como no caso de Ventura e Fim de rei Ottokar - usar línguas várias para dificultar a compreensão. O objeto parece ter sido usar a tradução em legendas para facilitar a apreensão da incompreensão vivida em cena pelos falantes de diversas línguas. E, a opção de legendas em alemão e inglês também é uma forma de multilinguismo teatral, remetendo ao multilinguismo fora do palco.

\section{Considerações finais}

A crescente heterogeneidade linguística na vida das pessoas que vivem no mundo globalizado tem trazido novas formas de se pensar e de se representar essa situação no palco. Nas duas peças aqui abordadas, a posição assumida de colocar em cena mais de uma língua (ou variante) não constitui apenas um retrato do mundo globalizado. Ela implica decisões de várias naturezas, inclusive políticas, que vão desde a escolha de diretores estrangeiros cuja origem acarreta uma nova visão sobre temática da respectiva peça, até a opção desses próprios diretores por atores estrangeiros e montagens multilíngues, lançando mão da carga emocional e significativa de pôr no palco línguas nem sempre compreendidas pela plateia. 
Para a tradução teatral, esse panorama traz uma nova situação: não se trata mais apenas de traduzir uma peça ou de legendar um drama integral em outra língua. Pode-se pensar também em traduzir uma peça monolíngue para outras línguas ou variantes de uma língua, todas faladas durante uma única montagem, acompanhadas ou não de uma tradução em legenda. A tradução pode ser usada também para produzir um texto (ou uma passagem) que, de modo proposital, deve ficar incompreensível para o público.

O mundo globalizado é multilíngue, e esse fato pode levar - ou não - a uma melhor compreensão entre os falantes dessas línguas. O teatro coloca esse assunto em cena. Nesse contexto, a tradução tem ganhado uma nova função: além de contribuir para a compreensão, é usada também para representar a não compreensão.

\section{Referências}

Affenzeller, Margarete. "Schräg: ,König Ottokars Glück und Ende“ im Volkstheater". Der Standard (9 de janeiro de 2019). Web 6 mai 2020. https:// www.derstandard.at/story/2000095786917/schraeg-koenig-ottokars-glueck-undende-im-volkstheater.

Baur, Detlev. "Reise nach Jerusalem. Wajdi Mouawad: Vögel". (16 de novembro de 2018). Web 3 fev 2020. https://www.die-deutsche-buehne.de/kritiken/reisenach-jerusalem.

Behrens, Marcus. "Theater als Form des Angriffs? Für Wajdi Mouawad reise ich auch nach Paris". 2019. Web 3 fev 2020. https://www.theaterbremen.de/de_DE/ theater-als-form-des-angriffs-fuer-wajdi-mouawad-reise-ich-auch-nach-paris.

Bernardes, Everton Mitherhofer. Língua, xenofobia e barbárie: uma proposta de tradução para a trilogia "O Velo de Ouro" de Franz Grillparzer. 2019. $116 \mathrm{f}$. 
Monografia (Bacharelado em Letras - Português e Alemão). Universidade Federal do Paraná, Curitiba, 2019. Web. 6 abr. 2020. http://www.humanas.ufpr.br/ portal/letrasgraduacao/curriculos/monografias/monografias-2019/.

Conter, Claude D. "Dramatik/Theater". Dembeck, Till; Parr, Rolf (org.). Literatur und Mehrsprachigkeit. Ein Handbuch. Tübingen: Narr Francke, 2017, p. $277-289$.

Davis, Natalie Zemon. Trickster Travels: A Sixteenth-Century Muslim Between Worlds. New York: Hill and Wang, 2007.

Dembeck, Till e Uhrmacher, Anne (org.). Das literarische Leben der Mehrsprachigkeit. Methodische Erkundungen. Heidelberg: Universitätsverlag Winter, 2016.

Griesel, Yvonne. Welttheater verstehen - Übertitelung, Übersetzen, Dolmetschen und neue Wege. Berlin: Alexander, 2014.

Kerlin, Alexander. "Identität - Sprache. Zusammengestellt von Alexander Kerlin”, Vögel Programa publicado em ocasião da estreia da peça em 13 de setembro de 2019. Viena: Akademietheater, 2019, p. 16-30.

Koberg, Roland. "Verlangen nach Volksnähe: Dušan David Pařízek im Gespräch mit Roland Koberg". König Ottokars Glück und Ende. Programa publicado em ocasião da estreia da peça em 8 de janeiro de 2019. Viena: Volksheater, 2019.

Magris, Claudio. Der habsburgische Mythos in der modernen österreichischen Literatur. Wien: Zsolney, 2000.

Mouawad, Wajdi. Vögel. Tradução de Uli Menke. Frankfurt am Main: Verlag der Autoren, 2018.

Paroni, Maurício. "Dramaturgo, dramaturg, dramaturgista". SP Escola de Teatro. (24 de outubro de 2017). Web 6 mai 2020. http://www.spescoladeteatro. org.br/coluna/dramaturgo-dramaturg-dramaturgista/. 
Weissmann, Dirk. "Vom Sprechenmitzwei Mündern: inszenierteSprachverwirrung und präbabylonisches Fremdverstehen in Yoko Tawadas zweisprachigem Theaterstück Till". . Das literarische Leben der Mehrsprachigkeit, Dembeck, Till; Uhrmacher, Anne. Methodische Erkundigungen. 2016, p. 165-194.

Recebido em: 19/11/2020

Aceito em: 11/03/2021

Publicado em maio de 2021

Ruth Bohunovsky. E-mail: ruth.bohunovsky@gmail.com. ORCID: https://orcid. org/0000-0003-4412-2678. 